\title{
THE EFFECTIVENESS OF BLIND CODES AND SECURITY FEATURES FOR THE BLIND AND THE PREVENTION OF FRAUD ON THE INDONESIAN RUPIAH ${ }^{1}$
}

\author{
Tri Hartono \\ Universitas 'Aisyiyah Yogyakarta \\ tri.hartono@unisayogya.ac.id \\ Fitra Roman Cahaya \\ roman.cahaya@uii.ac.id
}

\author{
ARTICLE INFORMATION \\ Article history: \\ Received August 07, 2017 \\ Revised Nov 12, 2017 \\ Accepted Dec 10, 2017 \\ JEL Classifications \\ K19; K42 \\ Key Words: \\ Blind Codes; \\ Security Features; \\ Ineffectiveness. \\ DOI: \\ 10.21532/apfj.001.17.02.02.04
}

\begin{abstract}
Blind codes and security features are very important for the people with visual impairment to recognize banknotes denomination. One of the problems commonly experienced by the blind Indonesian is how to detect the nominal value and the authenticity of the banknotes. It is suspected that blind codes and security features existing on the Indonesian banknotes are less effective to help the blind detect the banknotes.

That is why it is very interesting to analyze the level of effectiveness of blind codes and security features on the Indonesian banknotes, especially for the people with visual impairment. The experimental result shows that security features and blind codes are less effective for the people with visual impairment. It is assumed that the ineffectiveness will increase when the banknotes are in an outdated or crumpled condition. The authors gave treatment to respondents by giving Indonesian banknotes, which had been provided with Braille letter. Based on the experiment using Braille letter, 96\% of respondents were able to detect and enumerate the nominal value of the banknotes appropriately.

This ineffectiveness is feared to have an impact on the increasing circulation of counterfeit money in the community. It would be even more frightening when people become a medium of spreading counterfeit money in the community just because of the ineffectiveness of the design of banknotes and the lack of education of the blind Indonesian.
\end{abstract}

1 The Best Presenter of National Call For Paper ACFE Indonesia Chapter 2017 


\section{INTRODUCTION}

\section{Background}

In daily life, the means of payment used for getting something has been known for a long time. In the past, the Indonesian people knew the term of barter or an exchange of an object with another valuable item. It became a normal activity of its time. But along with the times, the barter has been no longer used by the people of Indonesia in the transaction process because it has been found a medium of exchange that has a certain value, that is, money.

The currency used in Indonesia today is Indonesian Rupiah (IDR). ${ }^{2}$ In its development, the Indonesian rupiah has undergone many design changes, either in the hero and color images or in the design for the purpose of security features and / or special markers for the blind ${ }^{3}$. The importance of security systems in currencies, especially banknotes, serves to facilitate the public to identify the authenticity of the money. Every banknote denomination issued and circulated by Bank Indonesia (BI) has certain features and security elements that are recognizable by its users. In addition to facilitate the public to recognize the characteristics of the authenticity of the banknotes, the element of protection is also intended to protect the banknotes from counterfeiting efforts.

Based on data from Bank Indonesia (BI) in March 2017, the amount of currency circulating in the community reached IDR 468.8 trillion (DSMF, 2017). With such a great nominal, there is a big possibility of counterfeiting banknotes. Until 2016, BI has recorded 222,211 pieces of counterfeit money, of which $0.05 \%$ of them are circulated in Yogyakarta Special Region (DIY). Judging the very large nominal circulation of counterfeit

\footnotetext{
2 According to the Law of the Republic of Indonesia Number 7 of 2011 on currency, the government authorized Rupiah as the prevailing currency in Indonesia, and then according to ISO 4217 abbreviated IDR (Indonesian Rupiah).

3 Some of the security features applied by BI to the banknote are reserved for the blind (DPU, 2015).
}

money in Yogyakarta, it is feared that in daily activities the people with visual impairment deal with counterfeit money, while they themselves are also business actors in their daily activities.

Special markers, such as security features and blind codes, are intended for people with visual impairment to identify both the nominal of currency and the authenticity of the currency (DPU, 2015) easily. However, in fact, there are still many people with visual impairment in Indonesia who are unable to maximize security features and blind code existing on the Indonesian banknotes. This concern is also based on some articles cited from Rahmayanti (2016) that the blind cannot recognize the nominal value of the banknotes well. In addition, Iswinarno (2014) also presented the results of socialization conducted by BI Purwokerto.

"Sometimes the payment should be IDR 35 thousand, but after being checked by my child, it is only IDR 25 thousand. In fact, when touching the money, it is also sometimes very difficult to recognize the value, because the money used is not new."

The number of people with visual impairment in Yogyakarta until 2016 was 2,758 (BPS DIY, 2017). Most people with visual impairment in Yogyakarta work as masseur and self-employed in other fields (see figure 2 ). By comparing the circulation of counterfeit money with the number of people with visual impairment in Yogyakarta, it is very risky if the productive blind people get counterfeit money in their daily activities due to the inability of the blind to identify security features and blind codes on the banknotes and due to the lack of socialization and the ineffectiveness of blind codes design on the banknotes. According to research conducted by Taylor (2006), the number of blinds has increased threefold.

\section{Identification of Problem}

To know the level of the effectiveness of the blind code on the banknotes, which is 
capable of reducing the level of incorrect nominal detection and authenticity of banknotes, can be analyzed based on several factors, such as:

a. The correct use of blind codes and security features.

b. The use of blind codes and security features by using Braille as a blind sign on the banknotes.

\section{Scope of Problem}

Based on the identification of the problem above, this study intends to test whether blind codes and security features on banknotes can be used effectively for people with visual impairment (total blindness).

\section{Formulation of the Problem}

This study examines how far blind codes and security features can be used as a medium to identify the authenticity and nominal value of banknotes. Therefore, the problem formulation in this study can be described in the following research questions:

a. Can the people with visual impairment identify the authenticity and nominal value of the banknotes using blind codes and security features?

b. Can the people with visual impairment identify the authenticity and nominal value of the banknotes using blind codes and security features written in Braille design?

\section{Research Purpose} determine:

The purpose of this research is to

a. The level of effectiveness of blind codes and security features on banknotes so that the blind can identify the authenticity and nominal value of the banknotes.

b. The level of effectiveness of blind codes and security features written in Braille design so that the blind can identify the authenticity and nominal value of the banknotes.

\section{Benefits of the Research}

This research is able to provide description and contribution related to blind codes and security features on the banknotes for several aspects such as:

a. Theory

This research is expected to contribute positively to the development of forensic accounting literature in Indonesia in the prevention of fraud and the manipulation of banknotes and other negative impacts. This statement assumes that the greater the number of people with visual impairments who know the functions of blind codes and security features on banknotes, the lower the circulation of counterfeit money in community.

\section{b. Practitioners}

This research is also expected to contribute to the effectiveness of government policy on banknotes design related to blind codes and security features. This research provides an idea to the government whether the design of blind codes and security features is effective for the blind.

\section{LITERATURE REVIEW}

\section{Blind Codes and Security Features}

According to article written by Clatchy (2006), some countries apply special designs and identifiers to banknotes to help people with visual impairment recognize the authenticity and nominal value of the banknotes. Like in Europe, banknotes are designed with a size difference between small nominal value of banknotes and large nominal value of banknotes. Japanese banknotes have a special texture on the tip of each nominal banknote. Meanwhile, Indonesian banknotes have blind 
Tri Hartono, Fitra Roman Cahaya : The effectiveness of blind codes and security.....

Page 165-173

codes and security features design which is the same as Japanese banknotes, that is, having a special texture on the banknotes (see picture 1).

\section{Figure 1}

Blind Codes and Security Features on Indonesian Banknotes

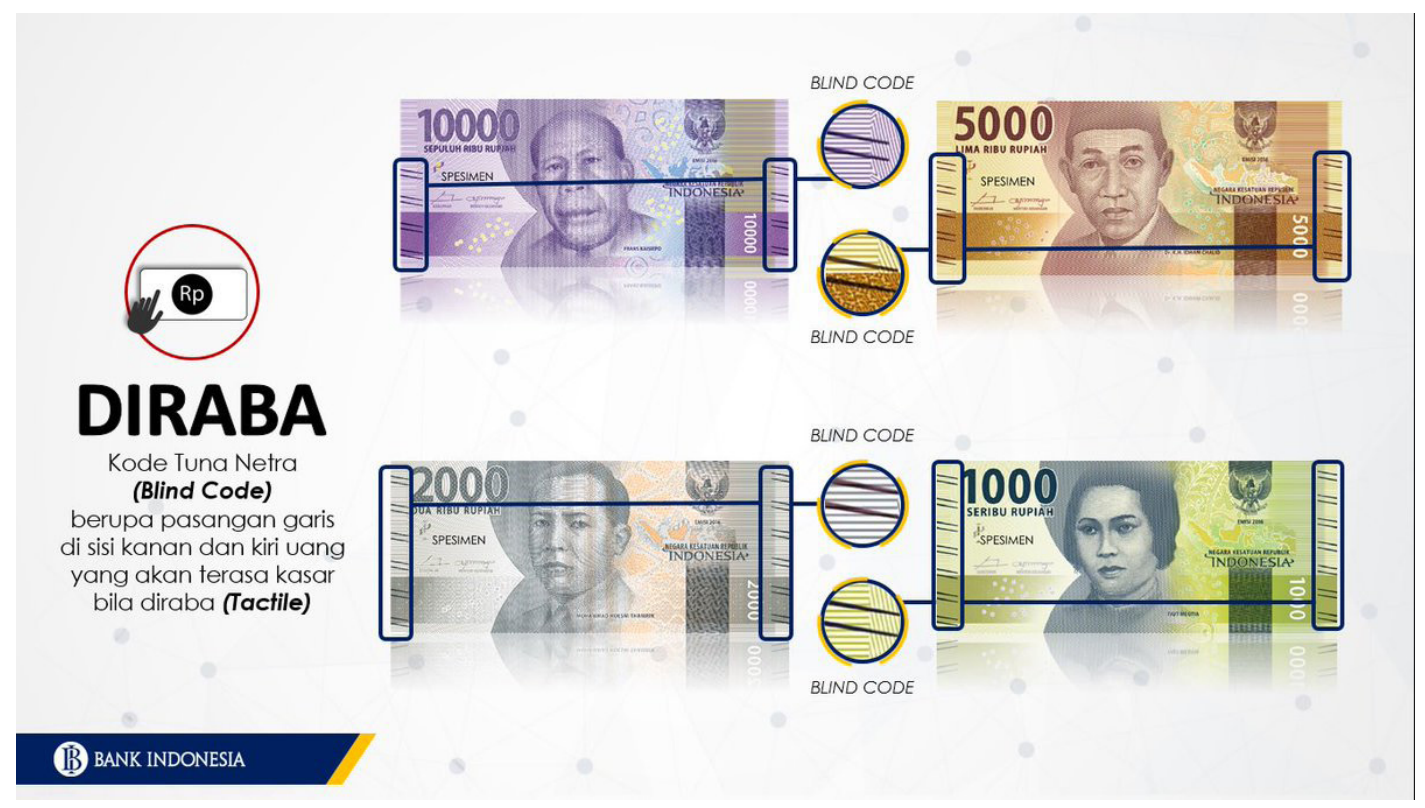

Source: DPU, Bank Indonesia, 2015

Special marks or blind codes on all new banknotes denomination of the Unitary State of the Republic of Indonesia (emission year 2016) for people with visual impairments are assured to last longer than the old banknotes denomination (Bisnis keuangan.Kompas, 2017). Blind codes and security features are special marks of the Indonesian banknotes deliberately designed to provide a special identifier that allows people to recognize the authenticity of banknotes and make it easier for people with visual impairment to recognize the nominal value of the banknotes.

According to Hadiprajitno (2017), there are 12 security features on banknotes emission year 2016, as follows:

a. Security feature using micro text.

b. Security feature using groping effect.

c. Security feature using recto-verso.

d. Security feature using latent image.

e. Security feature using color shifting.

f. Security feature using UV. g. Security feature using watermark.

h. Security feature using security thread

i. Security feature using blind code.

j. Security feature using overt.

k. Security feature using covert.

1. Forensic security feature.

Although there are many features contained in Indonesian rupiah banknotes, the authors assume that the features have not been maximized for people with visual impairment in Indonesia.

\section{People with Visual Impairment}

According to the data of the Central Bureau of Statistics of Yogyakarta (BPS DIY) in 2017, the number of people with visual impairment during the last ten years has decreased, or 2,758 people $(0.075 \%$ of total population of Yogyakarta). Population of Yogyakarta province is 3,679,179 people). When compared with the previous 3 years, in 2014, the number of blind people in Yogyakarta 
was 3,049 people. The biggest number of blind people in Yogyakarta resides in Gunungkidul Regency, reaching 921 people (for more details, see table 2)

\section{Table 2}

Blind People in Yogyakarta Special Region

\begin{tabular}{|c|c|c|}
\hline No & Regency & Total \\
\hline 1 & Kulonprogo & 465 \\
\hline 2 & Bantul & 592 \\
\hline 3 & Gunung Kidul & 921 \\
\hline 4 & Sleman & 633 \\
\hline 5 & $\begin{array}{c}\text { Yogyakarta } \\
\text { Municipality }\end{array}$ & 147 \\
\hline
\end{tabular}

Table 3

Trends in the Number of Blind (every three years)

\begin{tabular}{|c|c|c|}
\hline No. & Year & Total \\
\hline 1 & 2017 & 2,758 \\
\hline 2 & 2014 & 3,049 \\
\hline 3 & 2011 & 3,917 \\
\hline 4 & 2008 & 6,233 \\
\hline
\end{tabular}

Source: BPS Yogyakarta 2017

Some of the blind people in Yogyakarta are productive workers, where every day they deal with banknotes. From the initial observation, the profession widely experienced by the people with visual impairment is as a masseuse and trader (see picture 2). This becomes the authors' concern when the blind codes and security features on banknotes are not effective for the blind.
Figure 2

Profession of the People with Visual Impairment in Yogyakarta Special Region
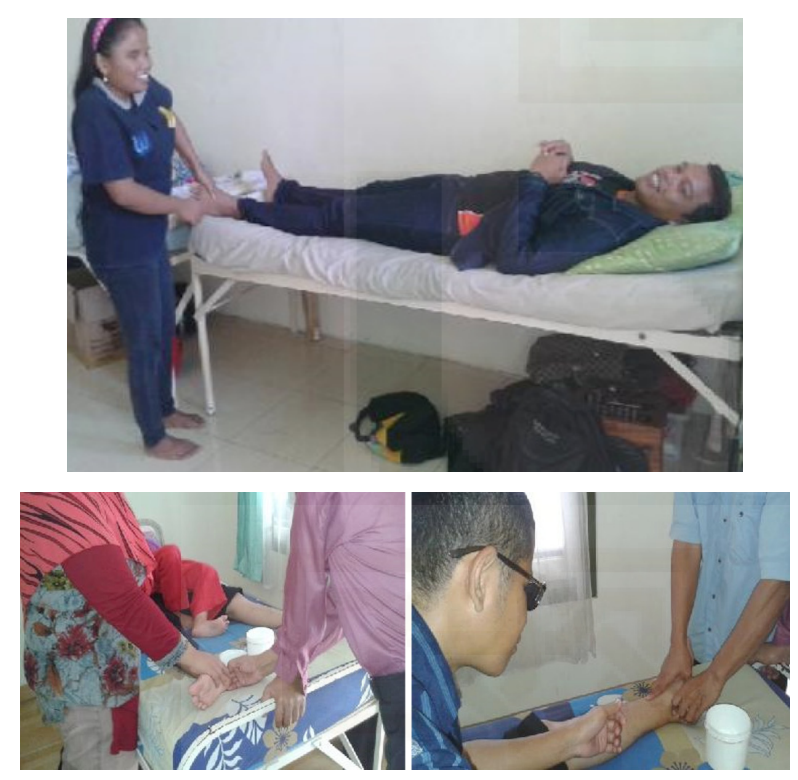

\section{RESEARCH METHOD}

\section{Research Stages}

This research has several stages of experiment arranged systematically by the authors as follows:

a. The authors collected data owned by 4 Persatuan Tunanetra Indonesia (PERTUNI) Yogyakarta Province.

b. The authors selected the research respondents based on the specified classification.

c. The research respondents were given original banknotes with different nominal values.

d. Next, the research respondents were given counterfeit banknotes with different nominal values.

e. The research respondents were asked to mention the nominal value and authenticity of the banknotes that had been given.

${ }_{4}$ The number of people with visual impairment in Yogyakarta Special Region, based on the data of BPS DIY of 2017, is 2.758 people. 
f. The research respondents were given original banknotes with different nominal values using Braille design.

\section{Research Site}

This research was conducted at Yayasan Kesejahteraan Tunanetra Islam (YAKETUNIS), located at Jalan Parangtritis No. 46, Danunegaran, Mantrijeron, Yogyakarta Province.

\section{Research Method and Design}

The methodology used in this research is an experimental method by observing 50 research respondents. The respondents were given three types of banknotes.

- The first type of banknotes is original banknotes worth IDR 1,000, IDR 2,000, IDR 5,000, IDR 10,000, IDR 20,000, IDR 50,000 and IDR 100,000.

- The second type of banknotes is counterfeit banknotes worth IDR 1,000 , IDR 2,000 , IDR 5,000, IDR 10,000 , IDR 20,000 , IDR 50,000, and IDR 100,000 .

- The third type of banknotes is original banknotes with Braille designs worth IDR 1,000, IDR 2,000, IDR 5,000, IDR 10,000, IDR 20,000, IDR 50,000, and IDR 100,000.

\section{Data collection and analysis techniques}

Data collection was conducted using direct observation technique at the time of experiment. By using experimental method, the researchers gave three treatments to the research objects as follows:

a. The first treatment (without any education about security features and blind codes)
1. First action (treatment using original banknotes):

Respondents were given original banknotes with nominal values of IDR 1,000, IDR 2,000, IDR 5,000, IDR 10,000, IDR 20,000 , IDR 50,000 and IDR 100,000. And then, they were asked to mention the nominal values of the banknotes given randomly. Each respondent was given 10 minutes to identify the nominal values of the banknotes given. Identification was done by groping the security features and blind codes existing on the original banknotes.

\section{Second action (treatment using counterfeit banknotes):}

Respondents were given counterfeit banknotes with nominal values of IDR 1,000 , IDR 2,000, IDR 5,000, IDR 10,000, IDR 20,000, IDR 50,000, and IDR 100,000. And then, they were asked to mention the authenticity of the banknotes given randomly. Each respondent was given 10 minutes to identify the nominal values of the banknotes given. Identification was done by groping the security features and blind codes existing on the counterfeit banknotes.

b. The second treatment (with education about security features and blind codes)

\section{First action (treatment using original banknotes):}

Respondents were given original banknotes with nominal values of IDR 1,000 , IDR 2,000, IDR 5,000, IDR 10,000, IDR 20,000, IDR 50,000, and IDR 100,000. And then, they were 
asked to mention the nominal values of the banknotes given randomly. Each respondent was given 10 minutes to identify the nominal values of the banknotes given. Identification was done by groping the security features and blind codes existing on the original banknotes.

\section{Second action (treatment using counterfeit banknotes):}

Respondents were given counterfeit banknotes with nominal values of IDR 1,000 , IDR 2,000, IDR 5,000, IDR 10,000, IDR 20,000, IDR 50,000, and IDR 100,000. And then, they were asked to mention the authenticity of the banknotes given randomly. Each respondent was given 10 minutes to identify the nominal values of the banknotes given. Identification was done by groping the security features and blind codes existing on the counterfeit banknotes.

\section{RESULTS AND DISCUSSION}

a. The first treatment (without any education about security features and blind codes)

\section{First action (treatment using original banknotes):}

The results of the experiments show that only 7 respondents $(14 \%)$ were able to identify the nominal values of the original banknotes through blind codes, while the remaining 43 respondents $(86 \%)$ were not able to identify the nominal values of the banknotes because they still did not know the blind-codes showing nominal values existing on the banknotes, emission 2016.

\section{Second action (treatment using counterfeit banknotes):}

The results of the experiment show that 9 respondents $(18 \%)$ were able to identify the authenticity of banknotes provided by using blind codes and security features, while the remaining 41 respondents $(82 \%)$ were not able to identify the authenticity of banknotes provided through the blind codes and security features because they still did not know the blind codes and security features showing authenticity existing on the banknotes, especially emission 2016.

Interestingly, 20 respondents failed to identify the authenticity of the banknotes. When they were given counterfeit banknotes and asked to identify the authenticity of the banknotes, they just mentioned that all the banknotes were original.

b. The second treatment (with education about security features and blind codes)

1. First action (treatment using original banknotes):

The results of the experiment show that only 21 respondents $(42 \%)$ were able to identify the nominal values of original banknotes through blind codes, while the remaining 29 respondents (58\%) were not able to identify the nominal values of original banknotes because the blind codes showing nominal values on the banknotes, especially emission 2016, were less sensitive when groped by a person with visual impairment, although the respondents had been given education about blind codes existing in the banknotes. It is feared that the blind codes will be less effective when the banknotes are in outdated or crumpled condition. 


\section{Second action (treatment using counterfeit banknotes):}

The results of experiment show that 32 respondents $(64 \%)$ were able to identify the authenticity of banknotes provided through blind codes and security features, while the remaining 18 respondents $(36 \%)$ were not able to identify the authenticity of banknotes through blind codes and security features, because the blind codes that indicate the authenticity of the banknotes, especially the 2016 emission were less sensitive when groped by the blinds. It is feared that the blind codes are increasingly ineffective when the banknotes are in outdated or crumpled condition. The results explain that education on security features and blind codes on people with visual impairment is not very significant in helping the blind people to identify the nominal value and authenticity of banknotes.

\section{c. The third treatment (Braille design as} blind code on banknotes)

Respondents were given a number of specially designed banknotes. There is Braille design on the banknotes. The special design indicates the numbers on the banknotes (see illustration in figure 3).

Figure 3

\section{Banknotes using Braille Design}

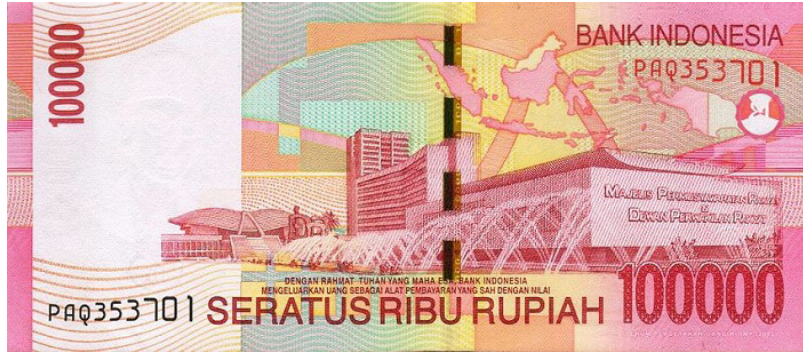

From the results of the first experiment, 40 respondents $(80 \%)$ were not able to identify the nominal values of the banknotes with the
Braille design because the respondents have not known the existence of the Braille design on the banknotes given. In the second experiment, the respondents were given different treatment. The respondents were given knowledge of the Braille design on the special banknotes. The knowledge given is as follows:

Figure 4

Braille Design on banknotes

\begin{tabular}{|c|c|c|}
\hline $\begin{array}{l}0 \\
\because \vdots \\
\vdots \\
\vdots \\
0\end{array}$ & 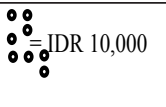 & 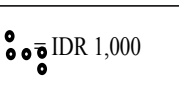 \\
\hline $\begin{array}{l}\because:=\text { IDR } 50.000 \\
\because 00 \\
\because 0\end{array}$ & $\begin{array}{l}\because 0=\operatorname{IDR~} 5.000 \\
\because \circ:\end{array}$ & $\begin{array}{l}\because \because=\text { IDR } 20.000 \\
\because 0 \\
0 \bullet:\end{array}$ \\
\hline
\end{tabular}

After the respondents were informed of the existence of Braille design on the banknotes, 2 respondents (4\%) were not able to identify the nominal values of banknotes given, 48 respondents $(96 \%)$ were able to mention the nominal values of the banknotes given correctly, and 43 respondents $(86 \%)$ were able to identify the authenticity of banknotes through Braille design.

From the results of these experiments, the authors assume that security features and blind codes contained in the banknotes are not effective for people with visual impairment, especially when the banknotes are in outdated or crumpled condition. It is feared to have an impact on the productivity of people with visual impairments in their daily economic activities. The authors also assume that the presence of Braille design on the banknotes will help the blind identify the nominal value and authenticity of the banknotes. This assumption is based on the results of experiments involving 50 adult blind-vision respondents at Yayasan Kesejahteraan Tunanetra Islam(YAKETUNIS).

The lack of effectiveness is feared to have an impact on the increasing circulation of counterfeit money in the community. It would be even more frightening if the blind people become a medium of spreading counterfeit 
money in the community just because of the ineffectiveness of banknotes design and the lack of education

\section{CONCLUSION}

Blind codes and security features on banknotes have a dominant function for the blind in identifying the nominal value and authenticity of a banknote. In addition, blind codes and security features are a sign of a country's honor in designing and facilitating all levels of society without exception. Based on this research results, it is expected that the government, through Bank Indonesia (BI) and Money Printing Company of the Republic of Indonesia (Perum Peruri) accommodate suggestions and inputs in this research. Hopefully, in the future the design of banknotes is friendly for anyone who uses it, no exception for people with visual impairment.

This study still needs improvement, especially in the number of respondents, because it is feared that there are still many respondents who do not recognize the Braille.

\section{REFERENCES}

Badan Pusat Statistik (BPS) DIY. 2017. Provinsi Daerah Istimewa Yogyakarta dalam angka 2016. BPS DIY

Depertemen Pengelolaan Uang (DPU). 2015. Unsur Pengaman Uang Rupiah. Bank Indonesia.

Divisi Statistik Moneter dan Fiskal (DSMF). 2017. Uang beredar (M2) dan faktor yang mempengaruhi. Bank Indonesia.

Frick, Kevin. 2012. What the comprehensive economics of blindness and visual impairment can help us understand. Indian Journal of Ophthalmology. Vol. 60 No.5

Iswinarno. 2014. Tuna netra masih kesulitan mengenali uang kertas. https://www. merdeka.com/peristiwa/. diakses pada 4 juni 2017.
Rahmayanti.2016. Sulitnya Mengenali Rupiah Bagi Tunanetra. http://koran-sindo.com/ page/rubric/2017-05-29/1/Opini. diakses pada 8 juni 2017.

Taylor, Hugh R. 2006. LXIII Edward Jackson Memorial Lecture: Eye Care: Dollars and Sense. American journal of ophthalmology. Vol. 143 No.1

Undang-Undang Republik Indonesia Nomor 7 tahun 2011 
Tri Hartono, Fitra Roman Cahaya : The effectiveness of blind codes and security.....

Page 165-173 